\title{
Condições de secagem de uma pasta de anchoita modificada enzimaticamente na oxidação lipídica, lisina disponível e atividade antioxidante do produto
}

\author{
Drying conditions of an enzymatic modified paste of anchovy in the lipid oxidation, available lisina and \\ antioxidant activity of the product
}

\author{
Kelly de Moraes $^{\mathrm{I}}$ Luiz Antônio de Almeida Pinto ${ }^{\mathrm{II}}$
}

\section{RESUMO}

\begin{abstract}
O objetivo do trabalho foi analisar as condições da secagem convectiva de uma pasta de anchoita (Engraulis anchoita) modificada enzimaticamente, através da metodologia de superfícies de resposta, sendo as respostas consideradas: a oxidação lipídica (TBA), a redução da lisina disponível e a perda da atividade antioxidante específica. A pasta de anchoita modificada foi obtida por hidrólise enzimática da fração muscular (filés) do pescado por Neutrase ${ }^{\circledast}$. Foram avaliadas na operação de secagem, a temperatura do ar $\left(60,70\right.$ e $\left.80^{\circ} \mathrm{C}\right)$ e a espessura das amostras (1,5; 2,5 e 3,5mm). A análise estatística da secagem mostrou efeitos significativos da temperatura do ar e da espessura das amostras $(P<0,05)$ nas respostas. A melhor condição de secagem foi obtida na temperatura do ar de $60^{\circ} \mathrm{C}$ e espessura das amostras de $2,5 \mathrm{~mm}$. Nessa condição, o índice de TBA foi de $0,93 \mathrm{mg}_{\mathrm{MDA}} \mathrm{kg}^{-1}$, redução da lisina disponivel de $16 \%$ e perda da atividade antioxidante específica de $20,2 \%$.
\end{abstract}

Palavras-chave: atividade antioxidante, Engraulis anchoita, enzima, oxidação lipídica, secagem convectiva.

\begin{abstract}
The aim of the work was to analyze the conditions of the convective drying of an enzymatic modified paste of anchovy (Engraulis anchoita) through the response surfaces methodology, and the responses were the lipid oxidation (TBA), reduction of the available lisina and loss of the specific antioxidant activity. The modified paste of anchovy was obtained through enzymatic hydrolysis of the fish muscular fraction (fillets) by Neutrase ${ }^{\circledR}$. In drying operation the air temperature (60, 70 and $\left.80^{\circ} \mathrm{C}\right)$ and the samples thickness $(1.5$, 2.5 and $3.5 \mathrm{~mm})$ were studied. The statistical analysis of the
\end{abstract}

drying showed significant effects of the air temperature and samples thickness $(P<0.05)$. The best drying condition was obtained in the air temperature of $60^{\circ} \mathrm{C}$ and samples thickness of $2.5 \mathrm{~mm}$. In this condition the TBA index was of $0.93 \mathrm{mg}_{\text {MDA }}$ $\mathrm{kg}^{-1}$, available lisina reduction of $16 \%$ and loss of the specific antioxidant activity of $20.2 \%$.

Key words: antioxidant activity, convective drying, Engraulis anchoita, enzyme, lipid oxidation.

\section{INTRODUÇÃO}

A anchoita (Engraulis anchoita) é uma espécie pelágica de elevada biomassa na costa brasileira, entretanto, seus estoques ainda permanecem inexplorados, mas com possibilidades de uma exploração sustentável. A anchoita mantém apenas pescarias de cunho artesanal com volumes muito abaixo em relação ao potencial de sua biomassa comprovada, que pode variar de 231 mil a 4,5 milhões de toneladas, entre o Brasil, o Uruguai e a Argentina. Dados mais recentes estimaram estoques na costa brasileira de aproximadamente 675,5 mil toneladas (PASTOUSMADUREIRA et al., 2009).

O processo de hidrólise tem sido desenvolvido para converter espécies de pescado subutilizadas e subprodutos da pesca em formas aceitáveis e comercializáveis. Na última década, além das atribuições de melhoramento de propriedades

\footnotetext{
'Programa de Pós-graduação de Engenharia e Ciências de Alimentos, Universidade Federal do Rio Grande (FURG), Rio Grande, RS, Brasil. "Escola de Química e Alimentos, FURG, Rua Engenheiro Alfredo Huch, 475, 96203-900, Rio Grande, RS, Brasil. E-mail: dqmpinto@furg.br. Autor para correspondência.
} 
funcionais tecnológicas e na biodisponibilidade de alguns nutrientes, as proteínas modificadas enzimaticamente (hidrolisadas) vêm sendo estudadas por apresentarem propriedades biológicas antioxidantes. As moléculas bioativas são grupos funcionais de proteínas e peptídeos, os quais são expostos ou liberados durante a hidrólise (FOH et al., 2010). A estabilidade oxidativa de alimentos está relacionada com o balanço entre fatores antioxidantes e pró-oxidantes. Operações de processamento aumentam o estresse oxidativo através da introdução de oxigênio, remoção de antioxidantes naturais, redução de antioxidantes endógenos e aumento de fatores próoxidantes (ELIAS et al., 2008).

A secagem ou desidratação tem sido utilizada por diversos países para preservar materiais biológicos e alimentícios. A remoção de umidade durante a secagem é muito afetada pela temperatura do ar e pelas características dimensionais do material, o que pode ocasionar alterações de qualidade no produto, como o aumento nos produtos de oxidação lipídica (OLIVEIRA et al., 2010). O efeito dos parâmetros de secagem na remoção de umidade, expressos por modelos cinéticos, tem sido estudado para diferentes espécies de pescado (PINTO \& TOBINAGA, 2006; VEJA-GÁLVEZ et al., 2011). A anchoita é uma excelente fonte proteica e rica em ácidos graxos poliinsaturados (CZERNER et al., 2011), assim, pode-se aproveitar o potencial de pesca da anchoita, utilizando a modificação enzimática de suas proteínas, associada à operação secagem para produzir um produto com melhores propriedades funcionais e nutricionais.

O objetivo do trabalho foi avaliar a influência das condições de secagem (temperatura do ar e espessura das amostras) de uma pasta de anchoita modificada enzimaticamente, obtida da hidrólise da fração muscular (filés), sobre atributos de qualidade do produto (oxidação lipídica, redução da lisina disponível e perda da atividade antioxidante específica), empregando como técnica a metodologia de superfície de resposta.

\section{MATERIAL E MÉTODOS}

\section{Material}

Para a realização do trabalho, foi utilizada a anchoita (Engraulis anchoita) na forma de uma pasta modificada enzimaticamente. A enzima utilizada no processo de modificação enzimática foi a Neutrase ${ }^{\circledR}$ 0,8L (Novozymes), que é uma endoprotease produzida pelo Bacillus amyloliquefaciens. Todos os reagentes utilizados foram de grau analítico.
A anchoita foi capturada em cruzeiro pelo "Navio Oceanográfico Atlântico Sul", utilizando rede de arrasto de meia água, na plataforma continental da região sul do Brasil. O preparo das amostras foi realizado segundo MORAES (2007), sendo as amostras de anchoita lavadas em água clorada (5ppm), evisceradas e filetadas, e os filés lavados novamente com uma solução de $\mathrm{NaCl} 0,3 \%$ e posteriormente com água deionizada. Após, foram drenados por $2 \mathrm{~h}$ sob refrigeração entre 4$7^{\circ} \mathrm{C}$ e posteriormente congelados a $-18^{\circ} \mathrm{C}$.

Obtenção da pasta modificada enzimaticamente

A partir dos filés de anchoita, obteve-se uma pasta modificada enzimaticamente de baixo grau de hidrólise (MBGH). Os filés foram descongelados sob refrigeração $\left(4-7^{\circ} \mathrm{C}\right)$ e hidrolisados por Neutrase ${ }^{\circledR} \mathrm{em}$ um biorretor de aço inoxidável, com agitação, ligado a um banho termostatizado. $O$ processo foi realizado em condições otimizadas por MORAES (2007), sendo em duas bateladas, com $250 \mathrm{~g}$ de filé cada, nas seguintes condições: $\mathrm{pH}$ do músculo 6,8 ; temperatura de $55^{\circ} \mathrm{C}$; razão enzima:substrato $(\mathrm{E} / \mathrm{S}) \mathrm{0,01 \%}$; tempo de hidrólise $30 \mathrm{~min}$. A inativação da enzima foi através do aquecimento da pasta obtida a $95^{\circ} \mathrm{C}$ por $5 \mathrm{~min}$. Ao final de cada batelada, foi medido o grau de hidrólise $(\mathrm{GH}) \mathrm{e}$ as duas pastas obtidas foram misturadas e armazenadas a $4^{\circ} \mathrm{C}$ por $24 \mathrm{~h}$, até o começo da secagem. O grau de hidrólise foi medido pela metodologia de ADLERNIESSEN (1979) através de reação do TNBS (ácido trinitrobenzeno sulfônico) com a leucina liberada durante a hidrólise, sendo dado como a relação entre o número de ligações peptídicas clivadas e o número total de ligações peptídicas.

Secagem da pasta de anchoita modificada

Os experimentos foram realizados em secador descontínuo de bandejas. O equipamento era constituído basicamente por um ventilador de 1,5HP e 1700rpm, e aquecimento elétrico de $6000 \mathrm{~W}$. A entrada e a saída do ar ocorriam por meio de tubulações providas de dampers, que permitiam regular a vazão de ar, sendo que o ar escoava paralelo sobre as bandejas. As dimensões das bandejas perfuradas, de aço inoxidável em forma retangular, foram $0,12 \mathrm{~m}$ de largura $0,14 \mathrm{~m}$ de comprimento. As espessuras das amostras foram de 1,5;2,5 e 3,5mm, resultando em massas de pasta na bandeja de 26,6; 44,3 e $62 \mathrm{~g}$, respectivamente. As temperaturas do ar de secagem foram de 60,70 e $80^{\circ} \mathrm{C}$, sendo esta faixa escolhida devido às amostras terem sido hidrolizadas, o que permitu o uso de maiores valores de temperatura. A velocidade do ar foi de $2,5 \mathrm{~m} \mathrm{~s}^{-1}$, a fim de desconsiderar os efeitos da resistência externa à transferência de massa (PINTO \& TOBINAGA, 
2006), e a umidade relativa foi determinada com termohigromêtro. As amostras foram pesadas em intervalos de tempo pré-estabelecidos em balança eletrônica, com precisão de $\pm 0,01 \mathrm{~g}$, até atingirem a umidade de $0,10 \mathrm{~kg} \mathrm{~kg}^{-1}$, conforme citado em MORAES (2007).

Após a secagem, os produtos foram submetidos às operações de moagem e peneiramento (Tyler 80-100). As amostras foram armazenadas em sacos plásticos fechados à pressão atmosférica, ao abrigo de luz e temperatura de $20^{\circ} \mathrm{C}$, sendo analisadas no dia subsequente à secagem. Todos os experimentos foram realizados em duplicata.

Metodologia Analítica

A pasta de anchoita modificada enzimaticamente foi caracterizada quanto à umidade, cinzas e proteína, segundo metodologias da AOAC (2000). Os lipidíos foram determinados segundo BLIGH \& DYER (1959). A oxidação lipídica foi avaliada através dos índices de TBA (ácido tiobarbitúrico). Os lipídios das amostras foram extraídos a frio, segundo BLIGH \& DYER (1959), com 50g de pasta modificada úmida e $10 \mathrm{~g}$ do produto seco. $\mathrm{O}$ índice de TBA foi determinado segundo VYNCKE (1970), sendo os resultados expressos em mg de malonaldialdeído por $\mathrm{kg}$ de amostra, em base seca. O conteúdo de lisina disponível foi determinado após a hidrólise da proteína com pepsina e pancreatina. A quantificação da lisina disponível, após a digestibilidade in vitro, foi através da reação colorimétrica da lisina com OPA (o-phtaldialdehyde), segundo DINNELLA et al. (2002). A atividade antioxidante específica (AAE) foi determinada segundo metodologias de FOH et al. (2010) e VÉGA-GALVEZ et al. (2011). A atividade antioxidante específica foi expressa como a quantidade do radical livre DPPH (1,1diphenyl-2picrylhydrazyl), sequestrado pela proteína em 30min. Todas as análises foram realizadas em triplicata.

Análise estatística

A avaliação das condições de secagem foi realizada através da metodologia de superfícies de resposta, aplicando-se um planejamento experimental fatorial completo $\left(3^{2}\right)$, casualizado, totalizando nove experimentos replicados (MYERS \& MONTGOMERY, 2002). Foram estudadas a influência da temperatura do ar de secagem $\left(\mathrm{X}_{1}\right)$ e da espessura das amostras $\left(\mathrm{X}_{2}\right)$, em três diferentes níveis equidistantes $(-1,0,+1)$. As variáveis independentes (fatores) foram escolhidas por serem importantes na secagem em camada delgada de alimentos ricos em proteínas (OLIVEIRA et al., 2010). Os valores reais dos fatores foram 60,70 e $80^{\circ} \mathrm{C}$ para a temperatura de secagem e 1,$5 ; 2,5$ e $3,5 \mathrm{~mm}$ para a espessura das amostras.

As respostas $\left(\mathrm{Y}_{\mathrm{n}}\right)$ para o planejamento foram avaliadas quanto às características do produto desidratado, sendo que o percentual de redução na atividade antioxidante específica (perda \% AAE) e o percentual de redução de lisina disponível (\% RLD) foram calculados em relação à pasta úmida e à oxidação lipídica (medida através da quantidade de TBA).

Os resultados da matriz do planejamento experimental foram analisados através de regressão não linear, utilizando um modelo de segunda ordem (Equação 1). A significância estatística dos coeficientes de regressão foi determinada pelo teste t-Student, a equação do modelo foi avaliada pelo teste de Fisher e a proporção da variância explicada pelo modelo foi dada pelo coeficiente de determinação $\left(\mathrm{R}^{2}\right)$. Para a realização da análise estatística dos resultados, foi utilizado o software Statistica 6.0 for Windows (StatSoft Inc, EUA). $Y_{n}=b_{0}+b_{1} X_{1}+b_{11} X_{1}^{2}+b_{2} X_{2}+b_{22} X_{2}^{2}+b_{12} X_{1} X_{2}$ em que $Y_{n}$ é a resposta predita (em valor real), $X_{1}$ é a temperatura na forma codificada, $\mathrm{X}_{2}$ é a espessura da amostra na forma codificada e $b_{n}$ são os coeficientes de regressão.

\section{RESULTADOS E DISCUSSÃO}

Caracterização da pasta modificada úmida

A caracterização da pasta úmida de anchoita modificada enzimaticamente quanto a sua composição centesimal (em base úmida - b.u) foi de: $79 \pm 1 \%$ de umidade, $17,3 \pm 0,9 \%$ de proteína, $1,3 \pm 0,2 \%$ de cinzas, $2,1 \pm 0,2 \%$ de lipídios. A umidade da pasta foi superior à observada em filés de anchoita frescos provenientes da Argentina, segundo dados relatados por CZERNER et al. (2011), o que consequentemente diminuiu os conteúdos (b.u) dos outros componentes, sendo que os conteúdos de proteína e lipídios da pasta (em base seca) foram inferiores em aproximadamente $12 \%$ e $30 \%$, respectivamente. Essas diferenças foram provavelmente devido ao local e época do ano da captura e das sucessivas lavagens dos filés.

O valor de TBA da pasta modificada úmida foi de $0,72 \pm 0,02 \mathrm{mg}_{\mathrm{MDA}} \mathrm{kg}^{-1}$, sendo este abaixo do limite recomendado de $2 \mathrm{mg}_{\mathrm{MDA}} \mathrm{kg}^{-1}$ (CONNELL, 1995), no qual o pescado desenvolve sabor e odor desagradáveis (ranço). $\mathrm{O}$ valor de lisina total da pasta modificada úmida foi de $0,091 \pm 0,001 \mathrm{mg}_{\text {lisina }} \mathrm{mg}^{-1}$, o de lisina disponível após digestibilidade in vitro da pasta foi de $0,085 \mathrm{mg}_{\text {lisina }}$ $\mathrm{mg}^{-1}$ e o de atividade antioxidante específica (AAE) da pasta úmida foi de $2,95 \pm 0,05 \mathrm{mM}_{\mathrm{DPPH}} \mathrm{g}^{-1} \mathrm{~min}^{-1}$. Proteínas 
podem apresentar atividade biológica, como, por exemplo, atividade antioxidante, que pode estar associada a peptídeos bioativos presentes em determinadas sequências da proteína, liberados após hidrólise (ELIAS et al., 2008).

\section{Otimização Estatística da Secagem}

A tabela 1 apresenta a matriz do planejamento experimental com os resultados da secagem da pasta modificada para as respostas índice de TBA, redução da lisina disponível (RLD) e perda da atividade antioxidante específica (AAE). A redução da lisina disponível (RLD), assim como a perda da atividade antioxidante específica (AAE) na pasta desidratada, foram calculadas em relação aos valores iniciais apresentados pela pasta modificada úmida.

A análise dos gráficos de pareto (Figura 1) foi utilizada para verificar a significância $(\mathrm{P}<0,05)$ dos efeitos principais da temperatura de secagem e da espessura da pasta e suas interações nas respostas. Para o índice de TBA (Figura 1(a)) e para a perda da AAE (Figura 1(c)), os efeitos lineares e quadráticos, tanto da temperatura quanto da espessura, foram significativos $(\mathrm{P}<0,05)$. Para a RLD (Figura 1(b)), os efeitos lineares da temperatura e da espessura e a interação entre eles foram significativos $(\mathrm{P}<0,05)$.

Os resultados obtidos para as respostas avaliadas (Tabela 1) foram ajustados pelo modelo quadrático (Equação 1), considerando apenas os efeitos significativos, conforme apresentado nas equações 2, 3 e 4, as quais representam as respostas para índice de TBA, redução da lisina disponível (RLD) e perda da AAE, respectivamente.
$\mathrm{Y}_{\mathrm{TBA}}=1,057+0,394 \mathrm{X}_{1}+0,151 \mathrm{X}_{1}^{2}-0,116 \mathrm{X}_{2}+0,513 \mathrm{X}_{2}^{2}$

$\mathrm{Y}_{\mathrm{RLD}}=27,088+10,470 \mathrm{X}_{1}+7,380 \mathrm{X}_{2}+1,932 \mathrm{X}_{1} \mathrm{X}_{2}$

$\mathrm{Y}_{\text {perdaAAE }}=25,648+8,924 \mathrm{X}_{1}+3,216 \mathrm{X}_{1}^{2}-4,122 \mathrm{X}_{2}+13,244 \mathrm{X}_{2}^{2}(4)$ em que $Y_{i}$ é a resposta (em valor real), $X_{1}$ e $X_{2}$ são as variáveis independentes (codificadas).

A validade dos modelos propostos foi verificada através de análise de variância e as regressões para valores de TBA, RLD e perda da AAE foram estatisiticamente significativas $(\mathrm{P}<0,05)$, com coeficientes de determinação $\left(\mathrm{R}^{2}\right)$ de 0,97; 0,97 e 0,99, respectivamente. Através do teste "F" de Fisher, verificou-se que os modelos apresentaram $\mathrm{F}_{\text {calculado }}$

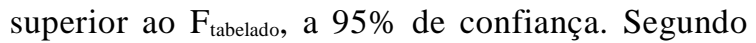
KHURY \& CORNELL (1996), um modelo teórico pode ser considerado preditivo quando o valor de $\mathrm{F}_{\text {calculado }}$ for 3-5 vezes superior ao valor de $F_{\text {tabelado. A figura } 2}$ apresenta as superfícies de resposta geradas pelos modelos estatísticos (Equações 2, 3 e 4), respectivamente, para TBA, RLD e AAE.

Na figura 2(a), os valores de TBA do produto, em todos os experimentos de secagem, foram superiores, quando comparados com o TBA da pasta modificada úmida $\left(0,72 \pm 0,02 \mathrm{mg}_{\mathrm{MDA}} \mathrm{kg}^{-1}\right)$. Os menores índices foram observados na menor temperatura e espessura intermediária. A maioria dos experimentos apresentaram qualidade oxidativa (TBA $\leq 2 \mathrm{mg}_{\mathrm{MDA}} \mathrm{kg}^{-1}$ ), com exceção da secagem na menor espessura e maior temperatura.

$\mathrm{Na}$ figura 2(b), pode ser observado que as menores reduções de lisina disponível (RLD) da pasta modificada, devido à secagem, foram em baixas temperaturas e menor espessura, sendo esses valores inferiores a $14 \%$. O efeito da temperatura foi mais pronunciado que o da espessura, isso também pode

Tabela 1 - Resultados da matriz do planejamento experimental fatorial para os experimentos de secagem da pasta de anchoita modificada enzimaticamente.

\begin{tabular}{cccccc}
\hline $\mathrm{N}^{\mathrm{o}}$ & \multicolumn{1}{c}{$\mathrm{X}_{1}$} & $\mathrm{X}_{2}$ & Índice TBA & Perda \\
& Temperatura & Espessura & $\mathrm{mg}_{\mathrm{MDA}} \mathrm{kg}^{-1}$ & Bs & AAE $(\%)$ \\
\hline 1 & -1 & -1 & $1,36 \pm 0,03$ & $12,35 \pm 0,58$ & $37,48 \pm 0,86$ \\
2 & -1 & 0 & $0,93 \pm 0,01$ & $15,96 \pm 0,46$ & $20,16 \pm 0,31$ \\
3 & -1 & 1 & $1,17 \pm 0,01$ & $21,94 \pm 0,29$ & $28,67 \pm 1,72$ \\
4 & 0 & -1 & $1,70 \pm 0,01$ & $16,36 \pm 0,52$ & $40,93 \pm 0,77$ \\
5 & 0 & 0 & $1,00 \pm 0,01$ & $28,22 \pm 0,40$ & $25,56 \pm 2,31$ \\
6 & 0 & 1 & $1,57 \pm 0,01$ & $33,74 \pm 0,81$ & $36,24 \pm 1,11$ \\
7 & 1 & -1 & $2,29 \pm 0,01$ & $30,25 \pm 0,81$ & $57,07 \pm 1,39$ \\
8 & 1 & 0 & $1,62 \pm 0,01$ & $35,25 \pm 0,69$ & $36,95 \pm 1,01$ \\
9 & 1 & 1 & $1,92 \pm 0,02$ & $47,57 \pm 0,69$ & $45,83 \pm 1,19$ \\
\hline
\end{tabular}

Média \pm erro-padrão de duas repetições (experimentos em duplicata e análises em tréplica);

RLD: redução da lisina disponível; AAE: atividade antioxidante específica; MDA: malonaldialdeído. 


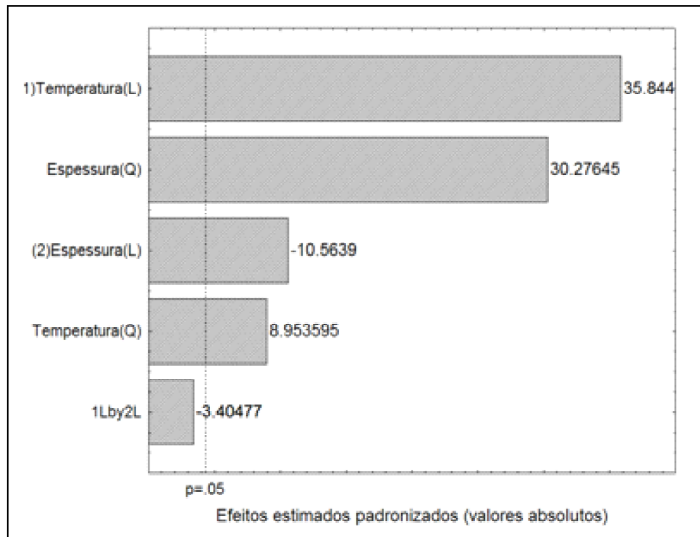

(a)

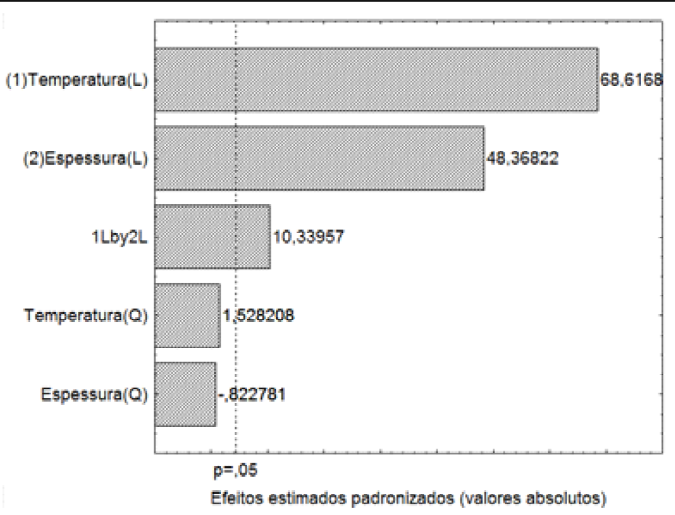

$(b)$

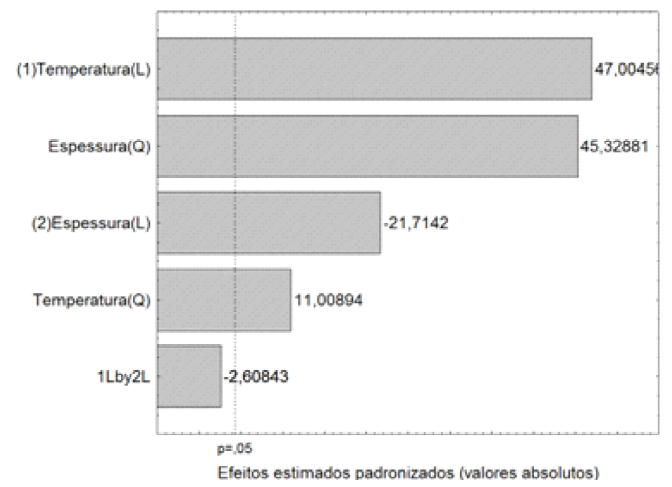

(c)

Figura 1 - Gráfico de Pareto da secagem de pasta de anchoita modificada enzimaticamente para os efeitos estimados padronizados das respostas: (a) índice de TBA; (b) redução percentual de lisina disponível, \% RLD; (c) perda percentual da atividade antioxidante específica, \% perda AAE.

ser observado na figura 1(b). Os aumentos da temperatura e da espessura das amostras na secagem causaram maiores reduções no conteúdo de lisina disponível, chegando a mais de $46 \%$. ABDUL-HAMID et al. (2002), estudando a secagem de hidrolisados de tilápia em spray dryer, observaram redução de aproximadamente $40 \%$ no total de lisina com o aumento na temperatura de saída do ar de $76^{\circ} \mathrm{C}$ para $90^{\circ} \mathrm{C}$.

A figura 2(c) mostra que a menor perda na atividade antioxidante específica (AAE) na secagem ocorreu na menor temperatura e espessura intermediária $(2,5 \mathrm{~mm})$. As maiores perdas foram na maior temperatura e espessura de 1,5 e $3,5 \mathrm{~mm}$. Na menor espessura, provavelmente, pode ocorrer maior exposição dos peptídeos bioativos e, na maior espessura, necessitase de um tempo maior de secagem até atingir umidade inferior a $10 \%$. Também pôde ser observado uma correlação entre menores perdas de atividade antioxidante (Figura 2(c)) e menores índices de TBA (Figura 2(a)), o que sugere que a proteína de anchoita modificada enzimaticamente tem um possível potencial de inibição da peroxidação lipídica. A habilidade das proteínas de remover radicais livres não é prova conclusiva de que elas são antioxidantes. Para um redutor de radicais livres ser um antioxidante eficaz em alimentos, deve ser mais oxidativamente lábil do que ácidos graxos insaturados, e o radical proteico resultante não deve ser forte o suficiente para promover a oxidação lipídica (ELIAS et al., 2008). Após a análise estatística realizada, definiu-se como a melhor condição de secagem a temperatura do ar de $60^{\circ} \mathrm{C}$ e a espessura da amostra de $2,5 \mathrm{~mm}$, sendo que nessa condição foram obtidos os menores valores de índice de TBA, RLD e perda da AAE. 


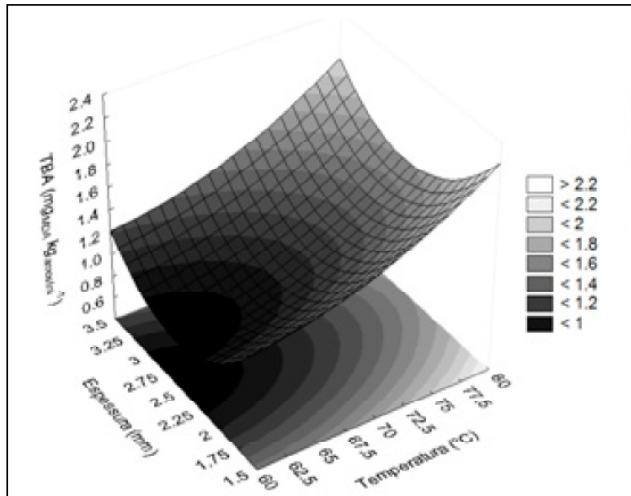

(a)

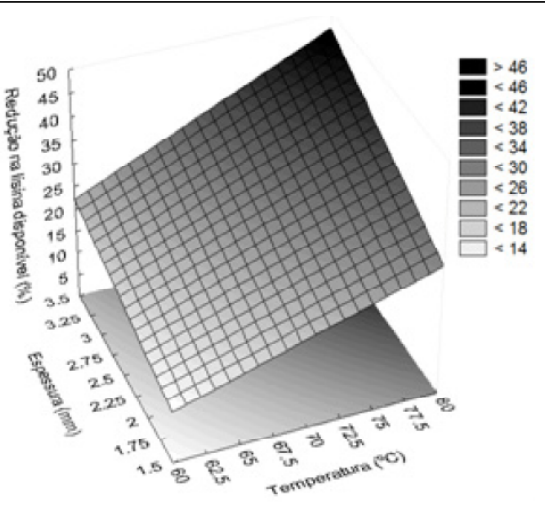

(b)

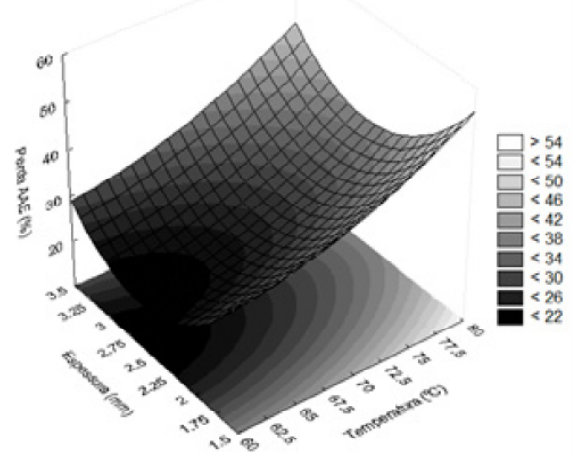

(c)

Figura 2 - Superfície de resposta da secagem de pasta de anchoita modificada enzimaticamente para: (a) índice de TBA; (b) redução percentual da lisina disponível, \% RLD; (c) perda percentual da atividade antioxidante específica, $\%$ perda AAE.

\section{CONCLUSÃO}

A análise estatística da secagem da pasta modificada obtida de filés de anchoita (Engraulis anchoita) hidrolisados por Neutrase ${ }^{\circledR}$ mostrou efeitos significativos da temperatura do ar e da espessura da amostra $(\mathrm{P}<0,05)$ nas respostas índice de TBA, redução da lisina disponível e perda da atividade antioxidante, medida através da redução do radical DPPH. A melhor condição de secagem estabelecida a partir da superfícies de resposta foi a temperatura do ar de $60^{\circ} \mathrm{C}$ e a espessura da amostra de $2,5 \mathrm{~mm}$. Nessa condição, o índice de TBA foi de $0,93 \mathrm{mg}_{\mathrm{MDA}} \mathrm{kg}^{-1}$, a redução da lisina disponível de aproximadamente $16 \%$ e a perda da atividade antioxidante específica de $20,2 \%$.

\section{AGRADECIMENTOS}

Os autores agradecem à CAPES (Coordenação de Aperfeiçoamento de Pessoal de Nível Superior), pelo suporte financeiro para o desenvolvimento deste trabalho.

\section{REFERÊNCIAS}

ABDUL-HAMID, A. et al. Nutritional quality of spray dried protein hydrolysate from black tilapia (Oreochromis mossambicus). Food Chemistry, v.78, p.69-74, 2002. Disponível em: <http://dx.doi.org/ 10.1016/S0308-8146(01)00380-66>. Acesso em: 15 maio, 2008. doi: 10.1016/S0308-8146(01)00380-6.

ADLER-NISSEN, J. Determination of the degree of hydrolysis of food protein by trinitobenzenesulfonic acid. Journal of Agricultural and Food Chemistry, v.27, n.6, p.1256-1262, 1979. Disponível em: 〈http://dx.doi.org/ 10.1021/jf60226a042〉. Acesso em: 10 abr. 2008. doi: 10.1021/jf60226a042.

AOAC. Association of Official Analytical Chemists. Official methods of analysis of A.O.A.C International. 17.ed. Gaithersburg, MD, 2000. 1170p.

BLIGH, E.G.; DYER, W.J. A rapid method of total lipid extraction and purification. Canadian Journal of Biochemistry and Physiology, v.37, p. 911-917, 1959. Disponível em: 〈http://dx.doi.org/ 10.1139/o59-099>. Acesso em: 20 mar. 2008. doi: 10.1139/o59-099. 
CONNELL, J.J. Control of fish quality. 4.ed. Surrey: Fishing News Books, 1995. 256p.

CZERNER, M. et al. Ripening of salted anchovy (Engraulis anchoita); development of lipid oxidation, colour and other sensorial characteristics. Journal of the Science of Food and Agriculture, v.91, p.609-615, 2011. Disponível em: <http://dx.doi.org/10.1002/jsfa.4221〉. Acesso em: 18 maio, 2011. doi: $10.1002 /$ jsfa.4221

DINNELLA, C. et al. Spectrophotometric assay using $o$ phtaldialdehyde for the determination of transglutaminase activity on casein. Food Chemistry, v.78, p.363-368, 2002. Disponível em: 〈http://dx.doi.org/10.1016/S0308-8146(02)00109-7>. Acesso em: 14 jun. 2009. doi: 10.1016/S0308-8146(02)00109-7.

ELIAS, R.J. et al. Antioxidant activity of proteins and peptides. Critical Reviews in Food Science and Nutrition, v.48, p.430-441, 2008. Disponível em: <http://dx.doi.org/10.1080/ 10408390701425615>. Acesso em: 14 fev. 2010. doi: 10.1080/ 10408390701425615 .

FOH, M.B.K. et al. Functionality and antioxidant properties of Tilapia (Orechromis niloticus) as influenced the degree of hydrolysis. International Journal of Molecular Sciences, v.11, p.1851-1869, 2010. Disponível em: <http://dx.doi.org/ 10.3390/ijms11041851>. Acesso em: 14 ago. 2010. doi: 10.3390/ijms 11041851 .

KHURY, A.I.; CORNELL, J.A. Response surfaces. 2.ed. New York: Marcel Dekker, 1996. 510p.

MYERS, R.H.; MONTGOMERY, D.C. Response surface methodology: process and product optimization using designed experiments. 2.ed. New York: John Wiley \& Sons, 2002. 798p.

MORAES, K. Desenvolvimento de um processo de obtenção de proteína de anchoita (Engraulis anchoita) modificada enzimaticamente. 2007. 120f. Dissertação
(Mestrado em Engenharia e Ciência de Alimentos) - Programa de Pós-graduação em Engenharia e Ciência de Alimentos, Universidade Federal do Rio Grande, RS.

OLIVEIRA, E.G. et al. Optimization of Spirulina platensis convective drying: evaluation of phycocyanin loss and lipid oxidation. International Journal of Food Science \& Technology, v.45, p.1572-1578, 2010. Disponível em: <http:/ /dx.doi.org/10.1111/j.1365-2621.2010.02299.x>. Acesso em: 14 dez. 2010. doi: 10.1111/j.1365-2621.2010.02299.x.

PASTOUS-MADUREIRA, L.S. et al. Current and potential alternative food uses of the Argentine anchoita (Engraulis anchoita) in Argentina, Uruguay and Brazil. In HASAN, M.R.; HALWART, M. (Eds.). Fish as feed inputs for aquaculture - practices, sustainability and implications. Rome: FAO. p.269287, 2009. (FAO Fisheries and Aquaculture Technical Paper, n.518). Acesso em: 20 jan. 2010. Online. Disponível em: <http://www.fao.org/docrep/012/i1140e/i1140e06.pdf>.

PINTO, L.A.A; TOBINAGA, S. Diffusive model with shirinkage in the thin layer drying of fish muscles. Drying Technology. v.24, p.509-516, 2006. Disponível em: <http:// dx.doi.org/10.1080/07373930600612040>. Acesso em: 07 jul. 2008. doi: 10.1080/07373930600612040.

VEGA-GÁLVEZ, A. et al. Effect of air temperature on drying kinetics and quality characteristics of osmo-treated jumbo squid (Dosidicus gigas). LWT-Food Science and Technology, v.44, p.16-23, 2011. Disponível em: <http://dx.doi.org/10.1016/ j.lwt.2010.06.012> Acesso em: 14 maio, 2011. doi: 10.1016/ j.lwt.2010.06.012.

VYNCKE, W. Direct determination of the thiobabituric acid value in trichoroacetic acid extracts of fish as a measure of oxidative rancidity. Fette-Seifen Anstrichmittel, v.12, p.1084-1087, 1970. Disponível em: <http://dx.doi.org/ 10.1002/lipi.19700721218>. Acesso em: 10 abr. 2008. doi: 10.1002/lipi.19700721218. 